OPEN ACCESS

Edited by:

Wanneng Yang,

Huazhong Agricultural University,

China

Reviewed by:

Weijuan Hu,

Institute of Genetics

and Developmental Biology, Chinese

Academy of Sciences, China

Xiaohui Yuan,

Wuhan University of Technology,

China

*Correspondence:

Stefan Gerth

stefan.gerth@iis.fraunhofer.de

${ }^{\dagger}$ These authors have contributed equally to this work

Specialty section:

This article was submitted to Technical Advances in Plant Science, a section of the journal

Frontiers in Plant Science

Received: 01 October 2020 Accepted: 11 March 2021

Published: 30 March 2021

Citation:

Van Harsselaar JK, Claußen J, Lübeck J, Wörlein N, Uhlmann N, Sonnewald U and Gerth S (2021)

$X$-Ray CT Phenotyping Reveals Bi-Phasic Growth Phases of Potato

Tubers Exposed to Combined Abiotic Stress. Front. Plant Sci. 12:613108. doi: 10.3389/fp/s.2021.613108

\section{X-Ray CT Phenotyping Reveals Bi-Phasic Growth Phases of Potato Tubers Exposed to Combined Abiotic Stress}

\author{
Jessica K. Van Harsselaar ${ }^{1 \dagger}$, Joelle Claußen ${ }^{2,3 \dagger}$, Jens Lübeck ${ }^{4}$, Norbert Wörlein ${ }^{2}$, \\ Norman Uhlmann ${ }^{2}$, Uwe Sonnewald ${ }^{1}$ and Stefan Gerth ${ }^{2 *}$
}

${ }^{1}$ Department of Biology, Friedrich-Alexander-University Erlangen-Nuremberg, Erlangen, Germany, ${ }^{2}$ Fraunhofer Institute for Integrated Circuits IIS, Development Centre X-Ray Technology, Fürth, Germany, ${ }^{3}$ School of Agriculture, Food and Wine, The University of Adelaide, Adelaide, SA, Australia, ${ }^{4}$ Solana Research GmbH, Windeby, Germany

As a consequence of climate change, heat waves in combination with extended drought periods will be an increasing threat to crop yield. Therefore, breeding stress tolerant crop plants is an urgent need. Breeding for stress tolerance has benefited from large scale phenotyping, enabling non-invasive, continuous monitoring of plant growth. In case of potato, this is compromised by the fact that tubers grow belowground, making phenotyping of tuber development a challenging task. To determine the growth dynamics of tubers before, during and after stress treatment is nearly impossible with traditional destructive harvesting approaches. In contrast, X-ray Computed Tomography (CT) offers the opportunity to access belowground growth processes. In this study, potato tuber development from initiation until harvest was monitored by CT analysis for five different genotypes under stress conditions. Tuber growth was monitored three times per week via CT analysis. Stress treatment was started when all plants exhibited detectable tubers. Combined heat and drought stress was applied by increasing growth temperature for 2 weeks and simultaneously decreasing daily water supply. CT analysis revealed that tuber growth is inhibited under stress within a week and can resume after the stress has been terminated. After cessation of stress, tubers started growing again and were only slightly and insignificantly smaller than control tubers at the end of the experimental period. These growth characteristics were accompanied by corresponding changes in gene expression and activity of enzymes relevant for starch metabolism which is the driving force for tuber growth. Gene expression and activity of Sucrose Synthase (SuSy) reaffirmed the detrimental impact of the stress on starch biosynthesis. Perception of the stress treatment by the tubers was confirmed by gene expression analysis of potential stress marker genes whose applicability for potato tubers is further discussed. We established a semi-automatic imaging pipeline to analyze potato tuber delevopment in a medium thoughput (5 min per pot). The imaging pipeline presented here can be scaled up to be used in high-throughput phenotyping systems. However, the combination with automated data processing is the key to generate objective data accelerating breeding efforts to improve abiotic stress tolerance of potato genotypes.

Keywords: X-ray, belowground, phenotyping, tuber (potato), genetic diversity, biomass, non-invasive (noncontact) measurements, abiotic stress 


\section{INTRODUCTION}

Independent climate change models predict that global temperatures will increase, and patterns of rainfall will change entailing periods of drought on the one hand and floods on the other hand (Cook et al., 2007). As a result, plants will be-and are already-exposed to changing environmental conditions which cause substantial yield losses (Hijmans, 2003; Ciais et al., 2005). The prevention of such losses is of particular importance regarding the rapidly growing world population and the increasing need for food and feed (Alexandratos and Bruinsma, 2012). Potato (Solanum tuberosum L.) is the fourth most important crop plant worldwide and as such of great significance with respect to food security (Thiele et al., 2010). Potato productivity is limited by abiotic stresses like drought and heat (Aksoy et al., 2015). Moreover, potato plants are cultivated worldwide including geographic areas that are prone to heat waves and drought periods. Therefore, potato yield is likely to be negatively affected by these stress factors alone or in combination.

Originating from the temperate zones of the Andes, potato plants prefer cooler temperatures below $20^{\circ} \mathrm{C}$ and a short photoperiod (12 h) (Van Dam et al., 1996). Potato tubers are formed by longitudinal cell division in pith and cortex from underground stem-derived shoots called stolons. Tuber formation is associated with increased cell expansion and division and an enhanced starch and storage protein biosynthesis and deposition. Sucrose unloading changes from apoplasmic to symplasmic (Viola et al., 2001) rendering Sucrose Synthase (SuSy) as the main enzyme hydrolyzing sucrose and thus providing building blocks for other metabolic processes like starch biosynthesis (Appeldoorn et al., 1997). As a consequence, SuSy has been identified as a determinant of sink strength (Zrenner et al., 1995). Both, heat and drought, have been shown to inhibit tuberization causing decreased tuber number, size and quality (Levy, 1985; Deblonde and Ledent, 2001). These adverse effects are caused by an interference of heat and drought with the formation of the tuberization signal SP6A (Navarro et al., 2011; Hastilestari et al., 2018), carbon allocation to developing tubers (Wolf et al., 1990; Gawronska et al., 1992), and tuber filling (Krauss and Marschner, 1984). In addition, starch mobilization has been described during both, heat and drought stress, leading to increased reducing sugar content of the tubers (Dahal et al., 2019).

Conventional methods to follow tuber growth over time involved the removal of tubers and/or alterations in the substrate leading to potential disturbances of source-sink relationships (Pérez-Torres et al., 2015). X-ray computed tomography (CT) is used to determine non-destructively and non-invasively above ground plant material for example of wheat ears (Hughes et al., 2017; Schmidt et al., 2020), rice tillers (Yang et al., 2011), or seeds (Duong Quoc Le et al., 2019). For belowground it is used to observe the soil root interactions (Rogers et al., 2016), the root systems (Tracy et al., 2010; Mooney et al., 2012; Zappala et al., 2013; Metzner et al., 2015; Pfeifer et al., 2015; Gao et al., 2019; Teramoto et al., 2020) or other plant organs like cassava or potato tubers (Pérez-Torres et al., 2015). Other methods to observe tuber growth dynamics non-destructively and noninvasively are magnetic resonance imaging (MRI) (Metzner et al., 2015; van Dusschoten et al., 2016) and ground penetrating radar (GPR) (Delgado et al., 2017). CT has previously been shown to allow non-invasive tracking of tuber growth and reproducible determination of tuber volume (Ferreira et al., 2010). A hindrance of this method was the high demand for manual corrections of the segmentation of the images which led to low sample throughput capacities, time-consuming data analysis and high costs.

Here we describe the implementation of a mediumthroughput imaging pipeline enabling us to continuously monitor growth of potato tubers by means of CT analysis. We observed the implications of combined heat and drought stress on tuber growth velocity in vivo and analyzed gene expression of potato tubers with destructive sampling.

\section{MATERIALS AND METHODS}

\section{Plant Material and Growth Conditions}

Solanum tuberosum plantlets of the cultivars Agria, Saturna, Tomensa, and Ramses were obtained from Solana Research GmbH (Windeby, Germany). The cultivar Diamant was obtained from KWS Potato BV (Nagele, Netherlands). All plantlets were propagated in tissue culture on MS-Medium (Murashige and Skoog, 1962) containing 2\% (w/v) sucrose under conditions of $16 \mathrm{~h}$ light $\left(150 \mu \mathrm{mol} \mathrm{m}^{-2} \mathrm{~s}^{-1}\right)$ and $8 \mathrm{~h}$ dark at $21^{\circ} \mathrm{C}$. Plants were transferred to individual pots with $15 \mathrm{~cm}$ diameter and a volume of 1.5 L containing sieved soil (Einheitserde Classic ED73; sieve grid $0.5 \mathrm{~cm}$ ). The pots were placed in plant growth chambers (Conviron, Winnipeg, Canada) under conditions of $16 \mathrm{~h}$ light at $21^{\circ} \mathrm{C}$ and $8 \mathrm{~h}$ dark at $18^{\circ} \mathrm{C}$ and $50 \%$ humidity during the day and $35 \%$ humidity at night. Plants were watered daily with $50 \mathrm{ml}$ per day/plant and tuber growth was monitored by CT three times per week. In the first experiment, four plants each of the cultivars Agria, Saturna, Tomensa, Ramses and Diamant were monitored at the same time. When tubers were detectable via CT, combined heat and drought stress was applied by increasing the temperature to $29^{\circ} \mathrm{C}$ during the light period and $21^{\circ} \mathrm{C}$ during the dark period and reducing the amount of water given to each plant from 50 to $30 \mathrm{ml} /$ day. In the second experiment with the cultivar Diamant, 30 plants were used of which 16 were monitored by CT analysis. After tuber initiation, as determined by CT monitoring, drought and mild heat stresses were applied to half of the plants for 2 weeks while the other half of the plants served as control group. The control group was watered with $50 \mathrm{ml}$ per day/plant for the whole time while the stress group was subjected to the conditions described above.

\section{X-Ray CT Imaging}

All plants were measured at an individually designed CT system at the Fraunhofer EZRT in Fuerth, Germany using a GE 225 MM2/HP source, Aerotech axis systems and the Meomed XEye 2020 Detector operating with a binned rectangular pixel size of $100 \mu \mathrm{m}$ (see Figure 1A). The source was operated at $175 \mathrm{kV}$ acceleration voltage with a current of $4.7 \mathrm{~mA}$, recording 800 individual projections with an integration time of $380 \mathrm{~ms}$ per 

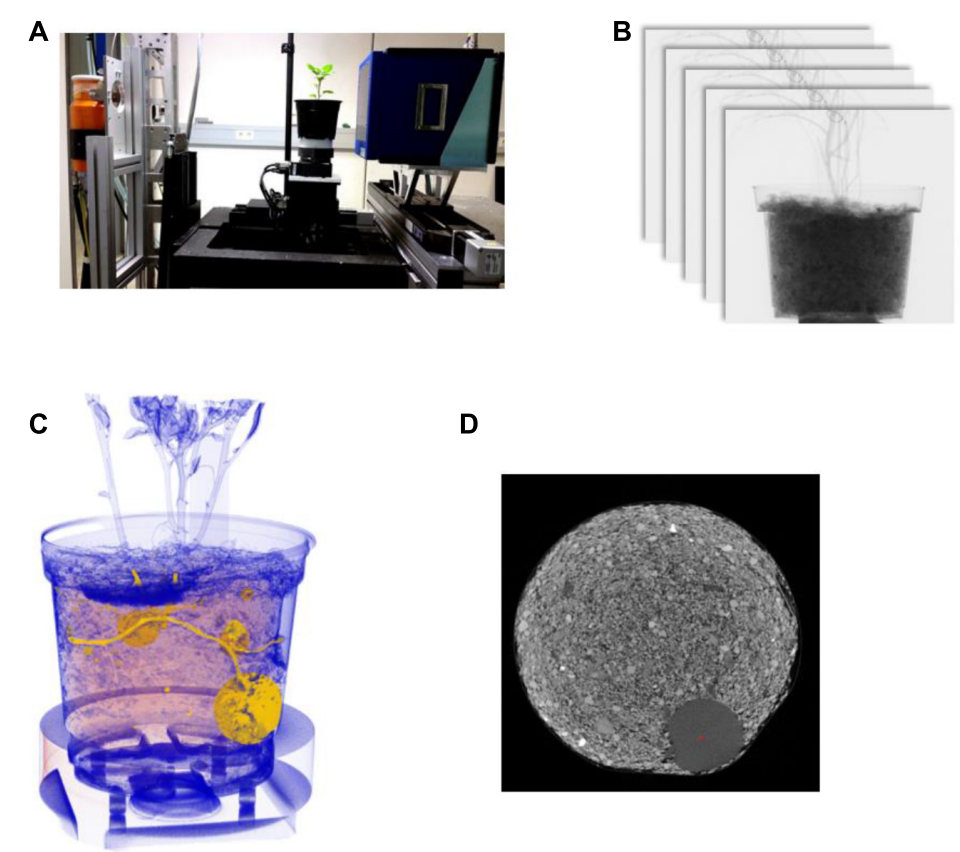

D

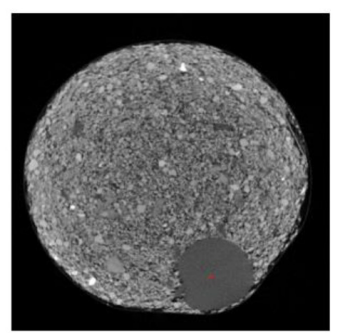

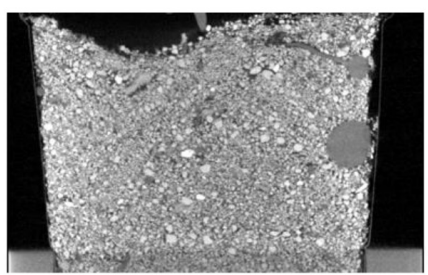

FIGURE 1 | Panel (A) shows a potato plant in the CT-System. On the left-hand side is the X-ray tube and on the right-hand side the detector, which collects the projections; panel (B) represents the stack of 2D projections; panel (C) shows a 3D visualization of the reconstructed and segmented data; (D) horizontal and (E) the vertical cross-section.

projection. The stack of projections was made with continuous sample rotation (fly-by) over $360^{\circ}$, resulting in a measurement time of $5 \mathrm{~min}$ per pot. To harden the x-ray spectra, a $1 \mathrm{~mm}$ thick copper pre-filtering was applied with the filter mounted directly in front of the source. For the reconstruction of the recorded projection stack (see Figures 1B,C), we used a filtered back projection reconstruction library from Fraunhofer EZRT. The algorithms are implemented following the description of Buzug (2008). For a stable analysis result, we normalized all reconstructed volumes regarding the unattenuated intensity of areas without any transmitted volume. Thus, the resulting gray-scale range is comparable throughout the whole series of measurements. In the CT system we used a focus object distance of $725 \mathrm{~mm}$ and a focus detector distance of $827 \mathrm{~mm}$. This resulted in a reconstructed voxel size of $88.9 \mu \mathrm{m}$. With this small distance between the pot and the detector, the resolution is mainly determined from the rectangular pixel size of the detector and not influenced from the focal spot size of the x-ray source. Thus, a scanning time of 5 min per pot is feasible. The loading of the potato pots was done manually (see Figure 1A). Figures 1D,E shows a horizontal and a vertical cross-section of the reconstructed volume, respectively.

\section{Implementation of an Automated Data Analysis Platform for CT Imaging}

We generated an automated data analysis platform for the high-throughput CT analysis. For better performance the image processing was done in a special $\mathrm{C}++$ application which can be used in the VolumePlayerPlus visualization and segmentation software. To analyze all plants in a comparable manner, special segmentation algorithms were used. Only using the reconstructed linear absorption coefficient, results in many false positives and it would be very hard to distinguish tubers from different plant material inside the soil (like turf, stolon and roots). Thus, we used the hypothesis that the soil is inhomogeneous compared to tubers for our image segmentation pipeline which contains eight steps (see Figure 2).

As first step after the reconstruction we applied a size adaptable median filter in $3 \mathrm{D}$ to reduce the noise. On this filtered volume we calculated pixel wise the local variance:

$V_{\text {local }}(x)=\frac{1}{\sqrt{2 \pi \lambda^{2}}} \exp \left(-\frac{\left(\mathbf{x}^{2}-\mathbf{x}_{\mathbf{0}}\right)^{2}}{2 \lambda^{2}}\right)-\left(\frac{1}{\sqrt{2 \pi \lambda^{2}}} \exp \left(-\frac{\left(\mathbf{x}-\mathbf{x}_{\mathbf{0}}\right)^{2}}{2 \lambda^{2}}\right)\right)^{2}$.

Now, compared to the soil, tubers are more homogeneous and a single threshold binarization separates most of the surrounding soil from the tubers. However, in this state potato tubers and stolons are still connected. Therefore, we applied a morphological operator called Erosion (Soille, 1998). As next step we calculated the connected components with a chessboard metric to have each object in the volume individually labeled and applied a morphological operator called Dilatation. This was necessary because the local variance calculation and the erosion reduced the size of the labeled segments. With the Dilatation we reversed this reduction and received the original size of the tubers.

At this stage only homogenously labeled objects were left over in the reconstructed dataset. For all of these objects, parameters like the volume, the mean absorption coefficient, the position 


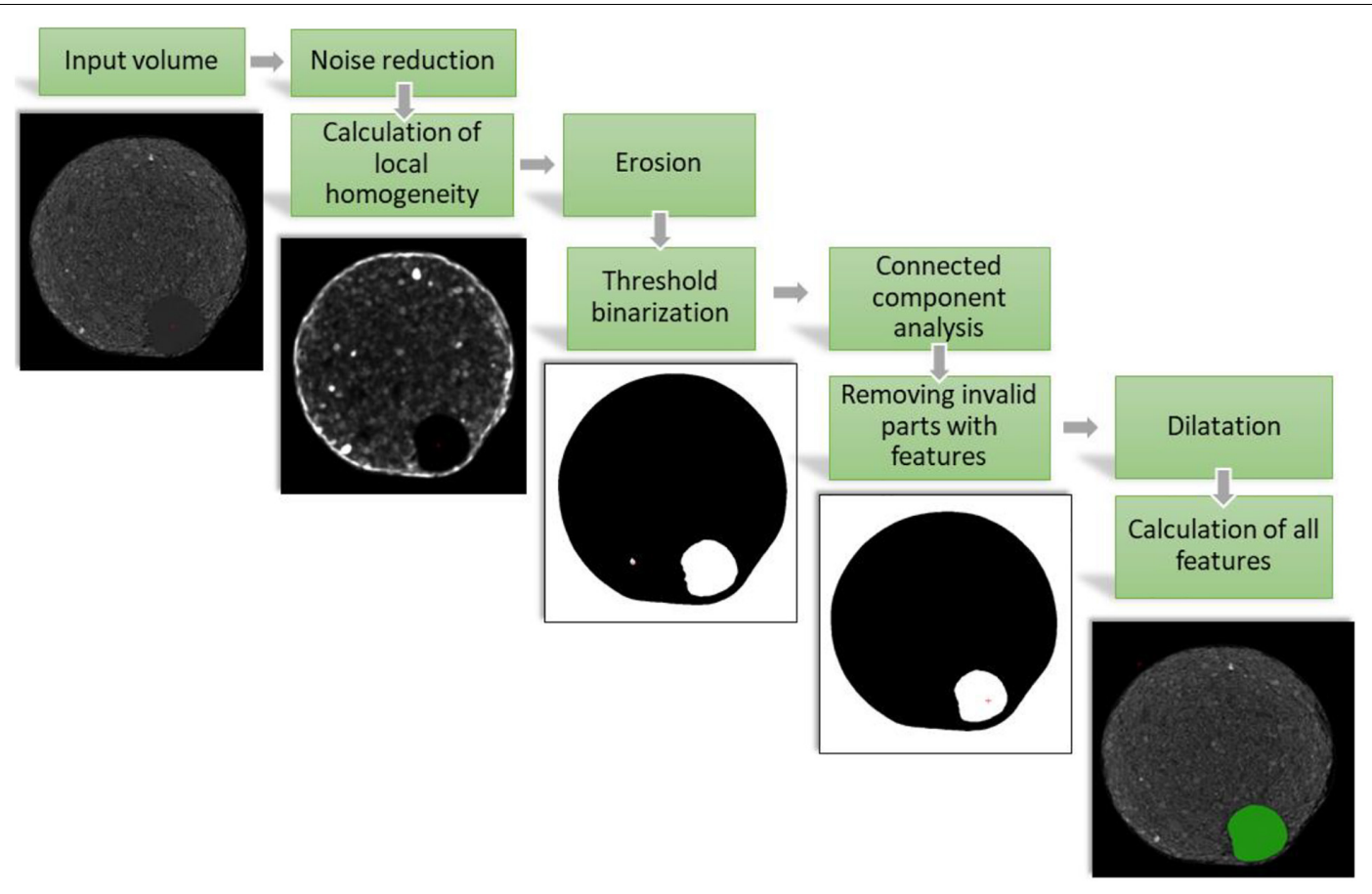

FIGURE 2 | Single steps of the image processing for segmenting potato tubers and the final segmentation as green overlay over the original volume. For representation virtual $2 \mathrm{D}$ cross sections at the same depth of the reconstructed 3D volume of the pot are shown.

and the aspect ratio were calculated. Scanning the same pot several times in a row, allowed to further differentiate between tubers and other false positive segmented homogenous objects like stones and parts of unconnected stolons. A tuber has to grow over time and the mean reconstructed absorption coefficient is depending on the material and density (Buzug, 2008), thus, it is possible to distinguish homogenous clay parts from the tubers. In case the aspect ratio is very different from a sphere all the disconnected homogenous stolons can be filtered as well. To track the potato tubers over time we calculated the center of mass of the individual potato tuber and compared it with the position of the timepoint before. The maximal distance was determined by the diameter of the sphere equivalent volume of the potato tuber at this timepoint. This resulted in a time dependent threshold of maximal difference between the center of mass of two timepoints.

Using these algorithms, it is possible to reconstruct, segment and analyze all plants at each measured time point with only one set of parameters. Both experiments combined 592 measurements in a total of 36 plants. An evaluation version of the Tuber segmentation package as well as some reference volumes can be obtained by the senior author (SG).

\section{Sampling of Tuber Material}

Tuber samples from the experiment with the cultivar Diamant were taken at three time points; (1) 8 days after initialization of the stress period, when the tubers had stopped growing (TP1), (2) 3 days after the stress period, when the tubers had started growing again (TP2), and (3) at the end of the experimental period, 2 weeks after the end of the stress phase (TP3). At each time point five plants per treatment were harvested and the leaf and tuber biomass were measured with a laboratory balance. At the first time-point, 10 plants (five per condition) were harvested which had not been monitored by CT analysis. At the second time-point, two plants per condition had not been subjected to CT analysis, while the other three sampled plants had been monitored. At the end of the experimental period the remaining 10 plants which had been monitored via CT imaging were harvested and biomass was determined. At each time point and condition, 10 tubers were selected for sampling. Samples were immediately frozen in liquid nitrogen and stored at $-80^{\circ} \mathrm{C}$ until further use.

\section{Determination of Starch Content}

Starch was quantified in tuber samples extracted with $80 \%$ ethanol incubated for $1 \mathrm{~h}$ at $80^{\circ} \mathrm{C}$. After centrifugation, removal of the supernatant, and washing with ethanol and water, $0.2 \mathrm{M}$ Hepes-KOH, pH 7.5 was added and samples kept at $4^{\circ} \mathrm{C}$ overnight. After heating the samples to $95^{\circ} \mathrm{C}$ for $1.5 \mathrm{~h}$, the $\mathrm{pH}$ was neutralized with $1 \mathrm{~N}$ acetic acid. Next, starch extracts were incubated with Amyloglucosidase overnight at $55^{\circ} \mathrm{C}$ and $\mathrm{pH} 5.5$. The spectrophotometric determination of released glucose was conducted as described previously (ap Rees et al., 1977).

\section{Measurement of Sucrose Synthase Activity}

Sucrose Synthase activity was measured according to Zrenner et al. (1995). Protein content was determined according to Bradford (1976). 


\section{RNA Isolation}

RNA was isolated as described previously (Logemann et al., 1987). Total RNA was quantified, and quality controlled using the ND-1000 Spectrophotometer (NanoDrop Technologies).

\section{CopyDNA Synthesis and Quantitative Reverse Transcriptase Polymerase Chain Reaction Analysis}

Two $\mu \mathrm{g}$ of total RNA were treated with DNase I (Thermo Scientific) prior to reverse transcription using oligo $\mathrm{d}(\mathrm{T})$ primers and RevertAid ${ }^{\mathrm{TM}} \mathrm{H}$ minus first strand copyDNA (cDNA) synthesis kit (Thermo Scientific) according to the manufacturer's instructions. For relative quantification of starch gene derived transcripts, quantitative reverse transcriptase polymerase chain reaction (qRT-PCR) analyses were performed using the AriaMX qPCR system (Agilent Technologies) in combination with the Brilliant II SYBR ${ }^{\circledR}$ Green QPCR Master Mix (Agilent Technologies) with four biological replicates for each condition and two technical replicates. Ubi3 [L22576, (Kloosterman et al., 2005)] expression was used for normalization of target gene expression. The thermal profile was as follows: 1 cycle $10 \mathrm{~min}$ at $95^{\circ} \mathrm{C}$ for DNA polymerase activation followed by 40 cycles of $30 \mathrm{~s}$ at $95^{\circ} \mathrm{C}, 30 \mathrm{~s} 60^{\circ} \mathrm{C}$ and $30 \mathrm{~s} 72^{\circ} \mathrm{C}$ and subsequently a melting curve. Primers were designed using the Primerdesigning tool on the NCBI website (Ye et al., 2012) to have a product length ranging from $70-150 \mathrm{bp}$ and a melting temperature from $59-61^{\circ} \mathrm{C}$. Target genes and sequences are listed in Table 1.

\section{RESULTS}

\section{Calibration of Tuber Fresh Weight From CT Analysis}

Analyzing the volume and the mean linear absorption coefficient for each tuber allows to calculate a virtual fresh weight. For this assumption we used the high correlation between the linear absorption coefficients of the reconstruction of the 3D volume with the physical density of the object. However, this only holds, as long as the elemental composition of the object of interest is more or less constant. In case of potato tubers, the elemental composition is mainly determined by hydrocarbon chains and water. In Figure 3, the correlation of the fresh weight with the non-destructively determined virtual fresh weight for individual potato tubers was calculated with an $\mathrm{R}^{2}$ of 0.99 .

Applying this as calibration, it was possible to directly calculate the corresponding fresh weight during the growth process for each measured tuber. With the results of the depicted image processing pipeline and the corresponding calculated features, a python script collected each single result and calculated the growth statistics over time for each potato tuber and variety.

\section{Growth Curves of Different Potato Varieties as Result of the Imaging Pipeline}

Potato plants were monitored via CT imaging every second day. After the measurement the potato tubers were virtually excavated out of the soil for each time point. This segmentation process was automated and ran with the same parameter for all plants even if there were differences in potato tuber sizes or in soil moisture due to stress conditions. Figure 4A demonstrates the segmentation process from plant to segmented tubers. Figure 4B depicts some timepoints of the growth of the potato tubers. The image from day 14 shows that the potato tubers can be segmented from the beginning where the potato tubers were only $3.6 \mathrm{~mm}$ in diameter. The image of day 42 demonstrates that even if there were several bigger potato tubers close together, the segmentation is possible. On the segmented tubers the volume and fresh weight of each tuber for each time point was calculated to determine the growth curve over time. Thus, each potato tuber could be tracked over the different measurements and even with slight variation in moisture content of the soil robust tuber tracking and segmentation was possible.

During the first experiment, five different genotypes were measured every second day from day 14 after planting until day 42 after planting. From day 15 after planting until day 29 after planting combined drought and heat stress was applied. The plants had between three and nine tubers which shows that the algorithm can segment the tubers even if the space between the tubers is restricted. In Figures 5A-E the growth analysis for the genotypes Agria, Saturna, Tomensa, Diamant and Ramses is shown, respectively. The subfigures represent the

TABLE 1 | Target genes and primer sequences for qRT-PCR analyses.

\begin{tabular}{|c|c|c|}
\hline Target gene & Forward primer sequence $\left(5^{\prime}-3^{\prime}\right)$ & Reverse primer sequence $\left(5^{\prime}-3^{\prime}\right.$ \\
\hline Ubiquitin (ubi3, L22576) & TTCCGACACCATCGACAATGT & CGACCATCCTCAAGCTGCTT \\
\hline Drought-induced 19 (DI19, PGSC0003DMT400011781) & CCAGTGCAGATCCTGATCCC & GCGCTाTतTGTGTTGAGCA \\
\hline Lipoxygenase 1 (LOX1, Sotub01g036960.1.1) & CAGAGCCAGGAAGTGCAGAG & TGAATCATTCTGCCCCAGGTAA \\
\hline $\begin{array}{l}\text { Abscisic acid and environmental stress-inducible protein (TAS14, } \\
\text { PGSC0003DMT400009069) }\end{array}$ & TAACACCTGTTGTGCCTCCA & CTTGGTTGCCGTATTGTGCC \\
\hline Heat-shock protein (HSP, PGSC0003DMT400032851) & GAAACACCTCAAGCTCATTGC & ТСТTСТGСТTССАСТTССА \\
\hline Sucrose Synthase 4 (SUSY4, PGSC0003DMT400007506) & ATGAACCGAGTGAGGAATGG & GCTGGACCACCGTGATTAGT \\
\hline Granule-bound starch synthase (GBSS, PGSC0003DMT400031568) & CTCACACAGCTCAACAAGTGC & GTGAAGCTGTGATGCTTGCC \\
\hline Glucose-phosphate Translocator 2.1 (GPT2.1, PGSC0003DMT400013500) & TGGCTGCTGGCTCTCTTATG & TGAGCCACAGCAACAGGAAA \\
\hline
\end{tabular}




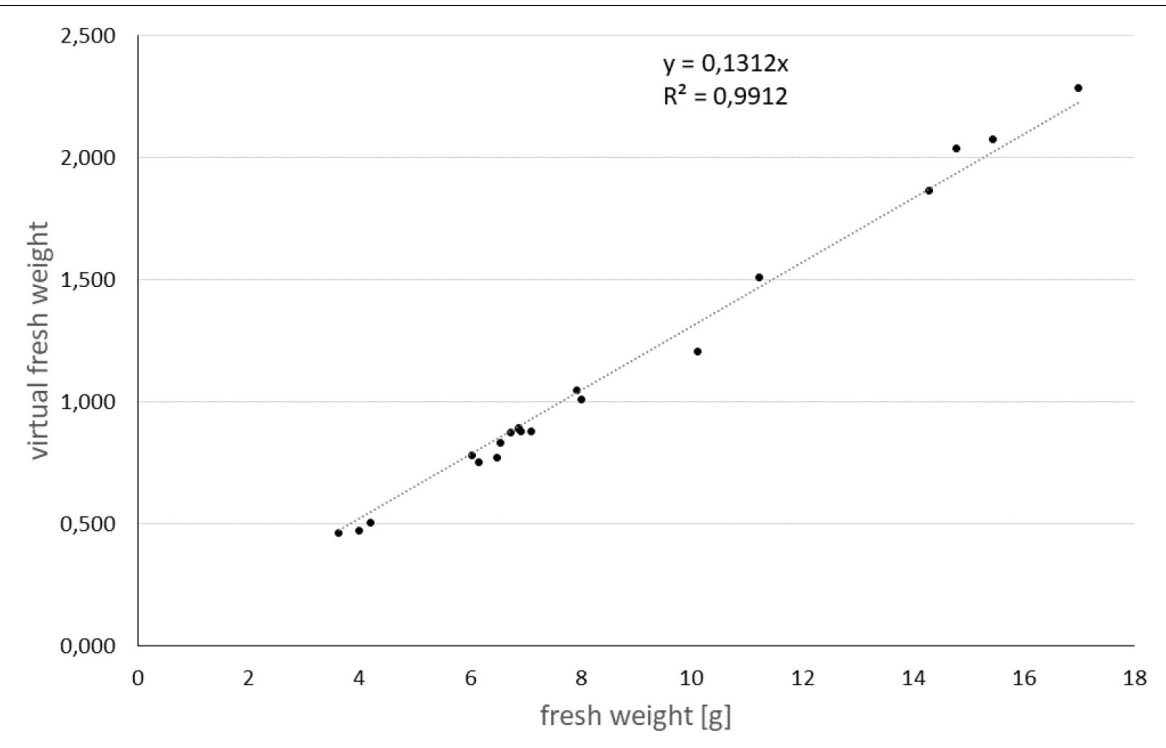

FIGURE 3 | Calibration curve for virtual tuber fresh weight to real tuber fresh weight.

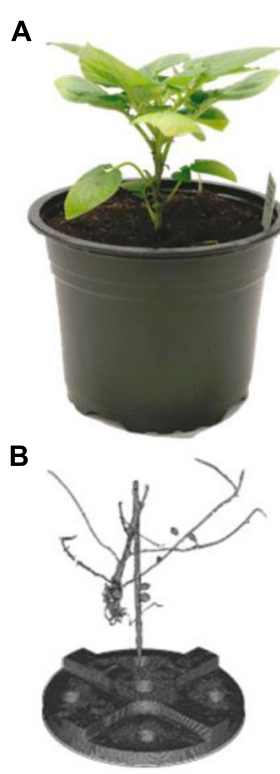

Day 14
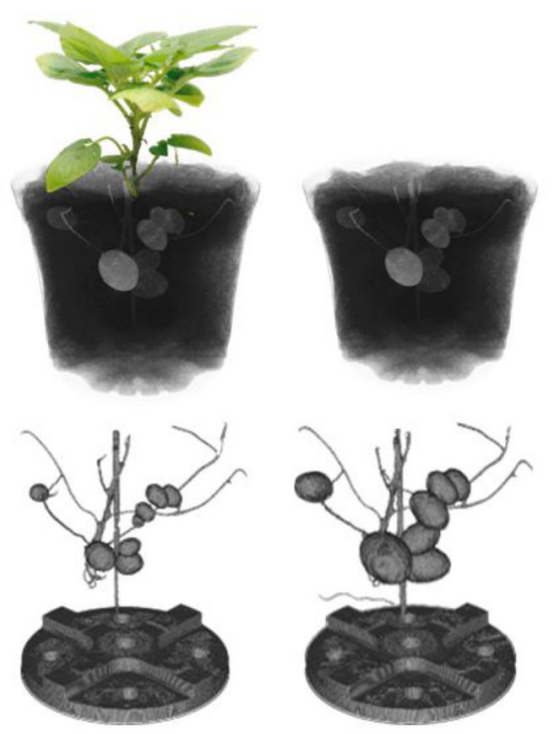

21

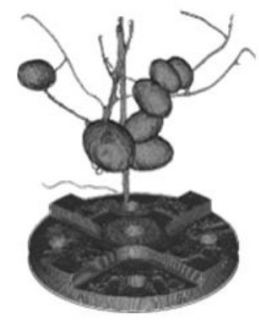

42
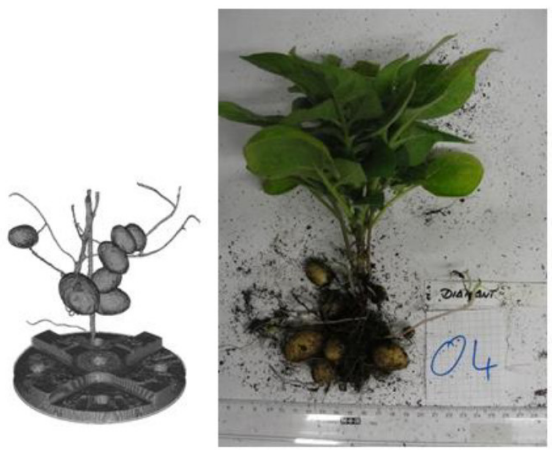

FIGURE 4 | Schematic representation of the virtual excavation of potato tubers using the automated segmentation process. The scanned plant is reconstructed after the CT measurement and virtually excavated. (A) On the right-hand side, the excavated tubers are shown after the last measurement time point. (B) three timepoints as example of the growth of the potato tubers.

growth of the tubers for one plant of the respective variety, exemplary. Each curve is related to one tuber of this particular potato plant. The growth curves clearly show that during the drought and heat stress the increase of volume is slower than in the recovery phase. Each genotype basically exhibited the same growth dynamic: In the first growth phase, tubers grew until stress treatment was started. In the second growth phase, after commencing the stress treatment, tuber growth slowed down and eventually stopped. In the last growth phase, after the stress was relieved, tubers resumed their growth. An unusual observation is that after the stress period there was at least one tuber which didn't continue growing. This was seen for all plants which had more than three tubers before stress application (Figures 5A-E).

Additionally, the total tuber biomass was calculated for each plant individually as the sum of all tuber weights of the respective plant at each time-point and the average total tuber fresh weight was calculated for all plants of the same 


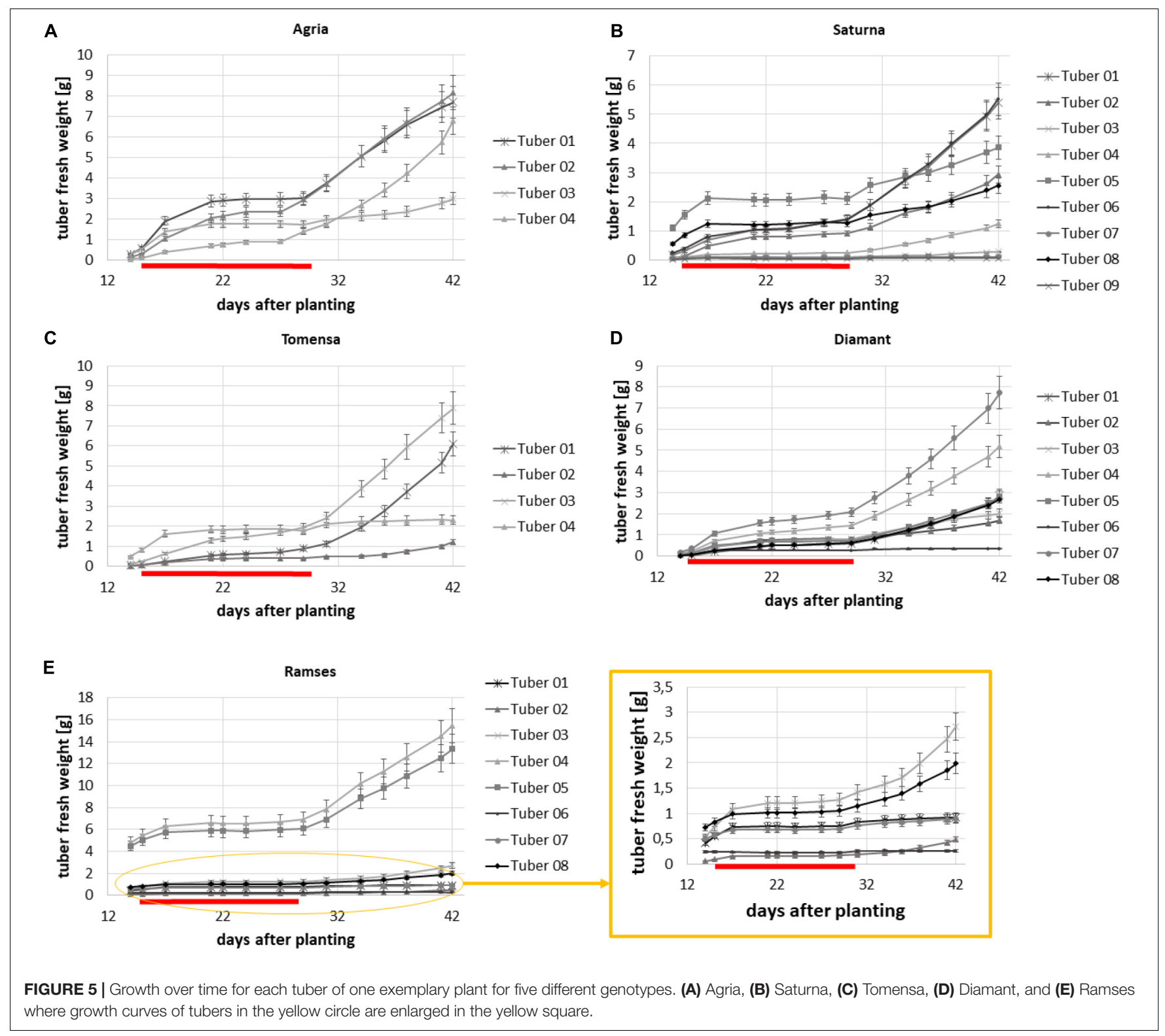

cultivar. For all genotypes analyzed, the increase of total tuber biomass stagnated during the combined abiotic stress treatment between days 15 and only very small increments in tuber biomass were observable (Figure 6B). After the stress treatment, tubers resumed growth in all cultivars. As shown in Figure 6A the resulting pattern of tuber biomass accumulation thus exhibited a bi-phasic course.

\section{Comparison of Tuber Growth Under Combined Heat and Drought Stress and Control Conditions}

To investigate whether the bi-phasic growth curve is a response to the combined heat and drought stress, a second experiment with only one genotype but with a control group was conducted. Therefore, thirty potato plants of the cultivar Diamant were grown in two phytochambers. Initially, the same temperature regime was applied to all plants until tubers developed i.e., $16 \mathrm{~h}$ light at $21^{\circ} \mathrm{C}$ and $8 \mathrm{~h}$ dark at $18^{\circ} \mathrm{C}$ and $50 \%$ humidity during the day and $35 \%$ humidity at night. Via the CT analysis pipeline, we monitored the tuber growth three times per week in 16 pots and utilized the same calibration set (see Figure 3) as in the previous experiment to estimate the individual tuber biomass from the volumetric data. The stress treatment was applied when all plants exhibited detectable tubers. After this, we applied to half of the plants a combined heat and drought stress by increasing ambient temperature to $29^{\circ} \mathrm{C}$ during the day and $21^{\circ} \mathrm{C}$ during the night for 2 weeks and simultaneously decreasing daily water supply to $30 \mathrm{ml}$ per day/plant instead of $50 \mathrm{ml}$ per day/plant for control conditions. A few days after commencement of the stress treatment, tubers in the stressed group of plants ceased growing (Figure 7A) while tubers in the 

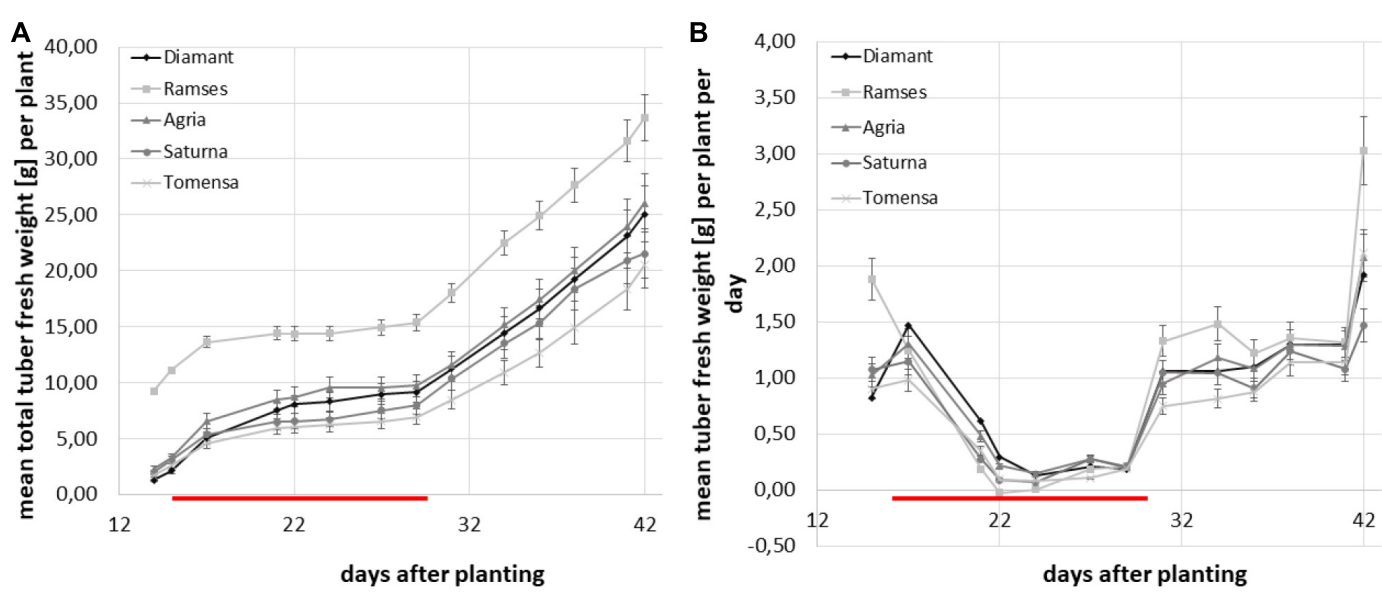

FIGURE 6 | Average total tuber mass per plant and genotype over the experimental time-course. Plants were grown in the greenhouse until tuber induction and then transferred to phytochambers under long day conditions. The red line indicates the period of elevated temperature and drought from day 15 to day 29 . Tuber growth was monitored three times per week in four plants of each of the cultivars; Diamant (diamond), Ramses (quadrat), Agria (triangle), Saturna (circle), Tomensa (cross). Error bars represent standard deviations of four biological replicates. (A) Average total tuber biomass per plant over the experimental time course; (B) average growth velocity of total tubers per plant in $\mathrm{g} / \mathrm{d}$.

A
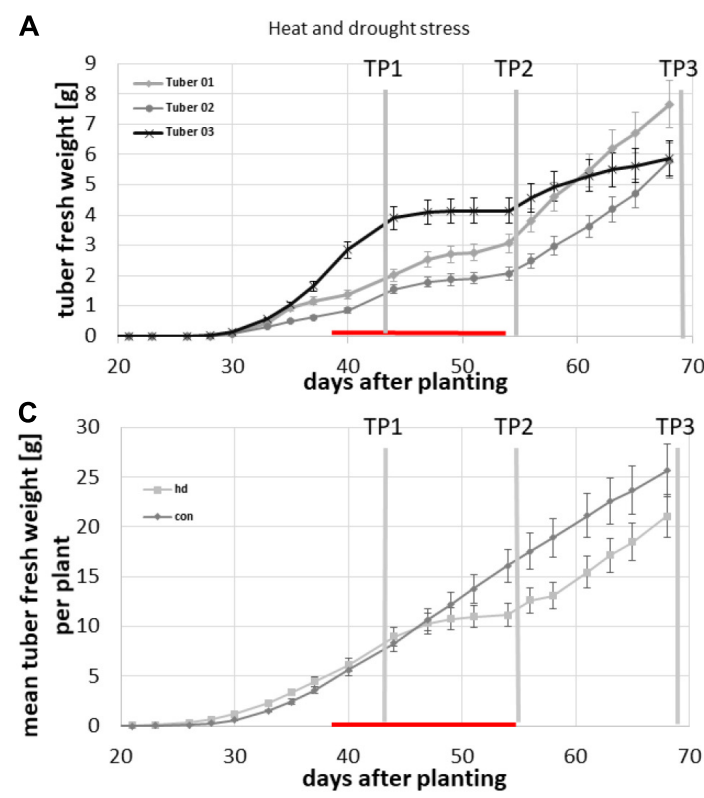

B
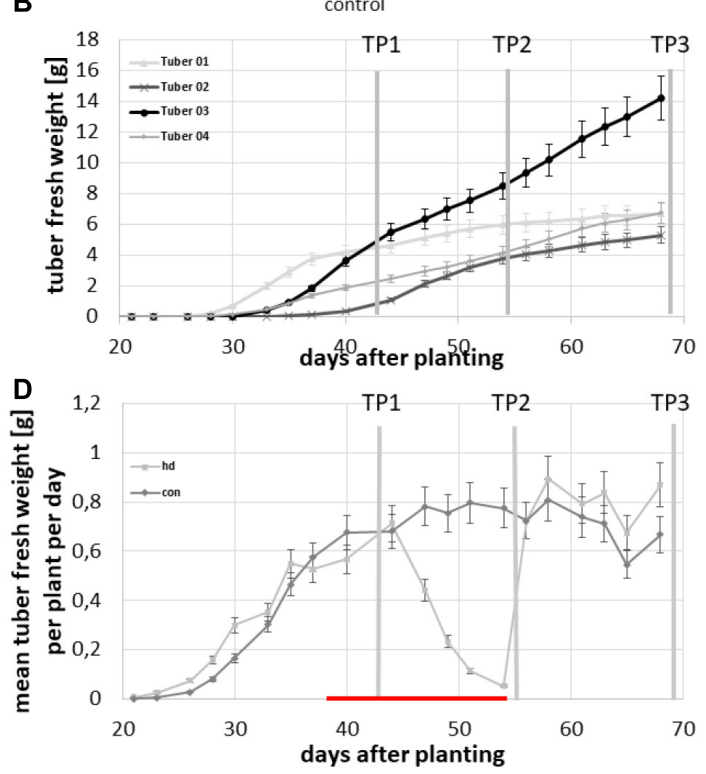

FIGURE 7 | Growth characteristics of potato tubers of cv. Diamant under normal plant growth conditions (con) and under combined heat and drought stress (hd). (A) Growth of each tuber of one plant of the stressed group, (B) growth of each tuber of one plant of the control group, (C) average total tuber fresh weight per plant over the experimental time course, and (D) average growth velocity of total tubers per plant in g/d. Error bars represent standard deviations of five to eight plants per treatment.

control group continued their growth (Figure 7B). Combined stress treatment led to a discontinuation of growth of all tubers, which is visible in Figure 7A, where all growth curves become flat. Control tubers showed constant growth although at varying velocities, as depicted in Figure 7B for tubers of one exemplary plant. This became clearly visible when average total tuber biomass per plant was calculated for each condition (Figure 7C) and, moreover, when the average biomass increase per day per plant was investigated (Figure 7D). Four days after the beginning of the stress treatment, a decrease in growth velocity was already measurable and it dropped close to zero at the end of the stress period. In contrast, tubers of plants kept under control conditions showed constant growth, which is depicted for the mean tuber biomass of monitored plants in Figure 7D. After releasing the plants from the stress treatment, growth velocity immediately increased to a level similar to that of the control treated plants resulting in a bi-phasic growth pattern (Figures 7C,D). 

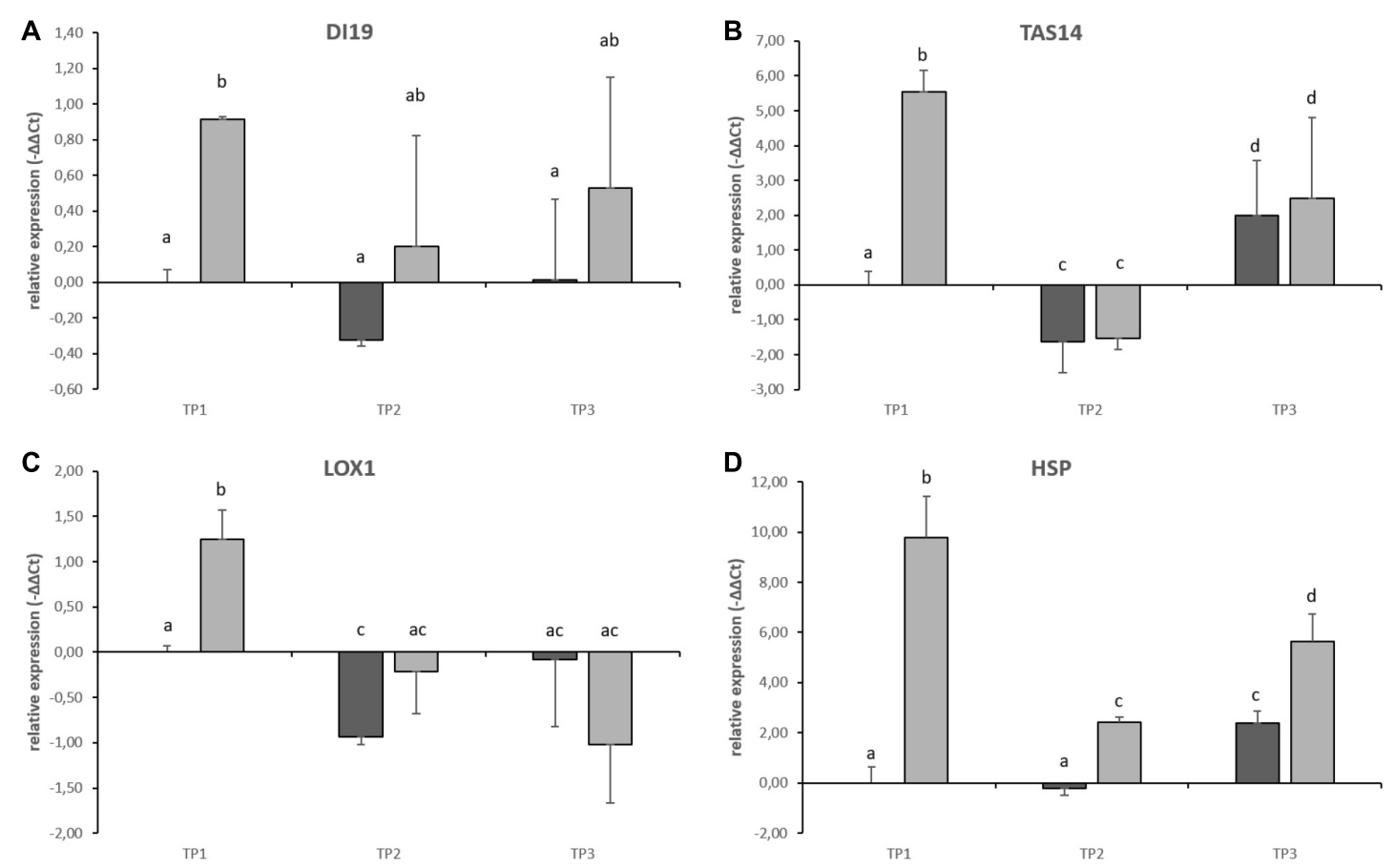

FIGURE 8 | qRT-PCR on stress-responsive gene expression in tuber samples of the potato cultivar Diamant. Results from control plants are shown in dark gray, stress treated plants are shown in light gray. Error bars represent standard deviation of three to four biological replicates. (A) Drought-induced 19 (DI19), (B) Abscisic acid and environmental stress-inducible protein (TAS14), (C) Lipoxygenase 1 (LOX1), and (D) Heat-shock protein (HSP). Different subscript letters indicate statistically different expression $(p<0.05)$.

\section{Abiotic Stress Marker Gene Expression Analysis Confirms Combined Stress Treatment}

To validate that the stress treatment had an effect on tuber physiology, the expression of potential marker genes for stress were investigated. Therefore, tuber samples taken 8 days after commencement of the combined stress treatment (TP1), 3 days after cessation of stress treatment (TP2) and after a 14day recovery phase at the end of the experimental period (TP3) were subjected to qRT-PCR analysis. Stress-responsive genes were selected from publications on drought stress and subsequent re-watering in potato stolons (Gong et al., 2015), potato plants exposed to elevated temperatures (Hancock et al., 2014) and combined heat and drought stress in tobacco (Rizhsky et al., 2002).

Gene expression of candidate stress marker genes droughtinduced 19 (DI19), Abscisic acid and environmental stress-inducible protein (TAS14), Lipoxygenase (LOX1), and Heat-shock Protein (HSP) was significantly increased during the heat treatment at TP1 when compared to potato tubers grown under control conditions (Figures 8A-D). After relieving the stress from the plants, gene expression of DI19, TAS14 and LOX1 decreased to control values (Figures 8A-C, TP2 and TP3). The only potential stress marker gene whose expression did not return to control values was a HSP whose expression stayed significantly above control values until the end of the experimental period although to a lesser extent as during the stress treatment at TP1 (Figure 8D). The expression of DI19 was significantly increased during the stress treatment but showed a lot of variation after stress release at TP2 and 3 (Figure 8A) indicating that individual tubers adjust differently to the changed environmental conditions.

\section{Impact of Combined Stress on Starch Metabolism}

Abiotic stress is known to cause yield penalties and quality loss in potato (Levy, 1985, 1986). Since starch content is the main factor determining potato tuber dry matter and an important trait for breeders ( $\mathrm{Li}$ et al., 2008), the impact of the stress treatment on starch metabolism was investigated. Therefore, activity of sucrose synthase, a marker enzyme for starch biosynthesis (Zrenner et al., 1995; Baroja-Fernández et al., 2009) was measured. In comparison to the plants grown under control conditions, SuSy-activity was decreased during the stress treatment and remained low throughout the rest of the experimental period (Figure 9A). In contrast, when measuring starch contents of the tubers at the three time-points, no significant changes were detected (Figure 9B).

To further elucidate the impact of the stress treatment on starch metabolism, gene expression of SuSy4, the main SuSy isoform in potato tubers (Fu and Park, 1995; Van Harsselaar et al., 2017) and a determinant of sink strength (Zrenner et al., 1995) was evaluated via qRT-PCR analysis. During the stress 

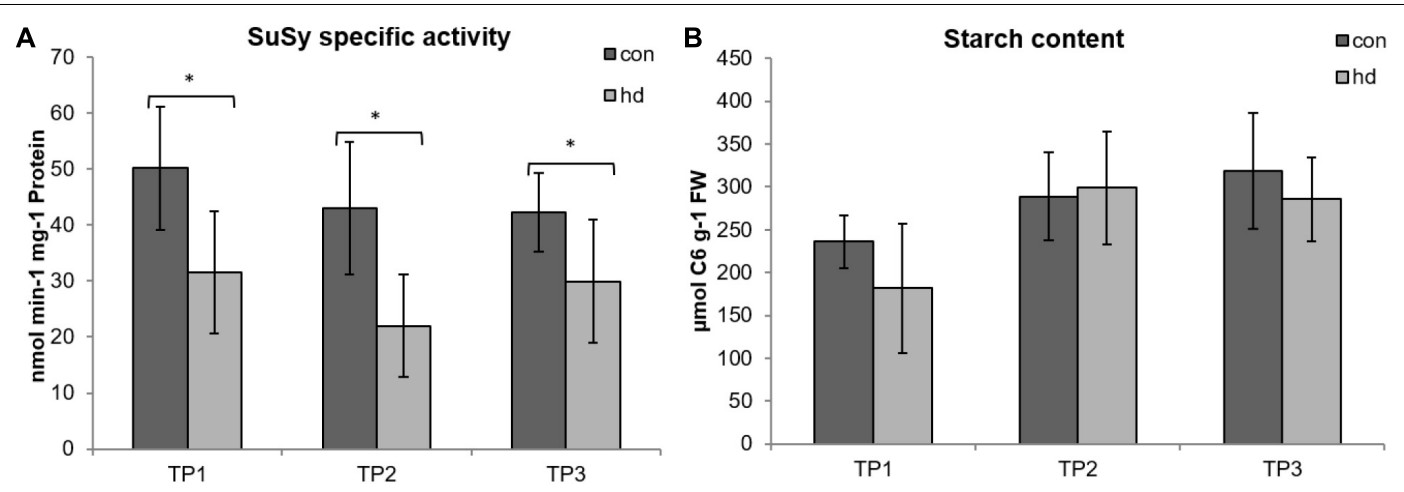

FIGURE 9 | SuSy-activity (A) and starch content (B) of tubers from plants grown under control and combined stress conditions. Dark gray bars represent values from control treated plants; light gray values represent values from stressed plants. Error bars represent standard deviations of nine to 10 biological replicates and six to 10 biological replicates for SuSy and starch measurements, respectively ( ${ }^{\star} p<0.05$, Student's $t$-test).

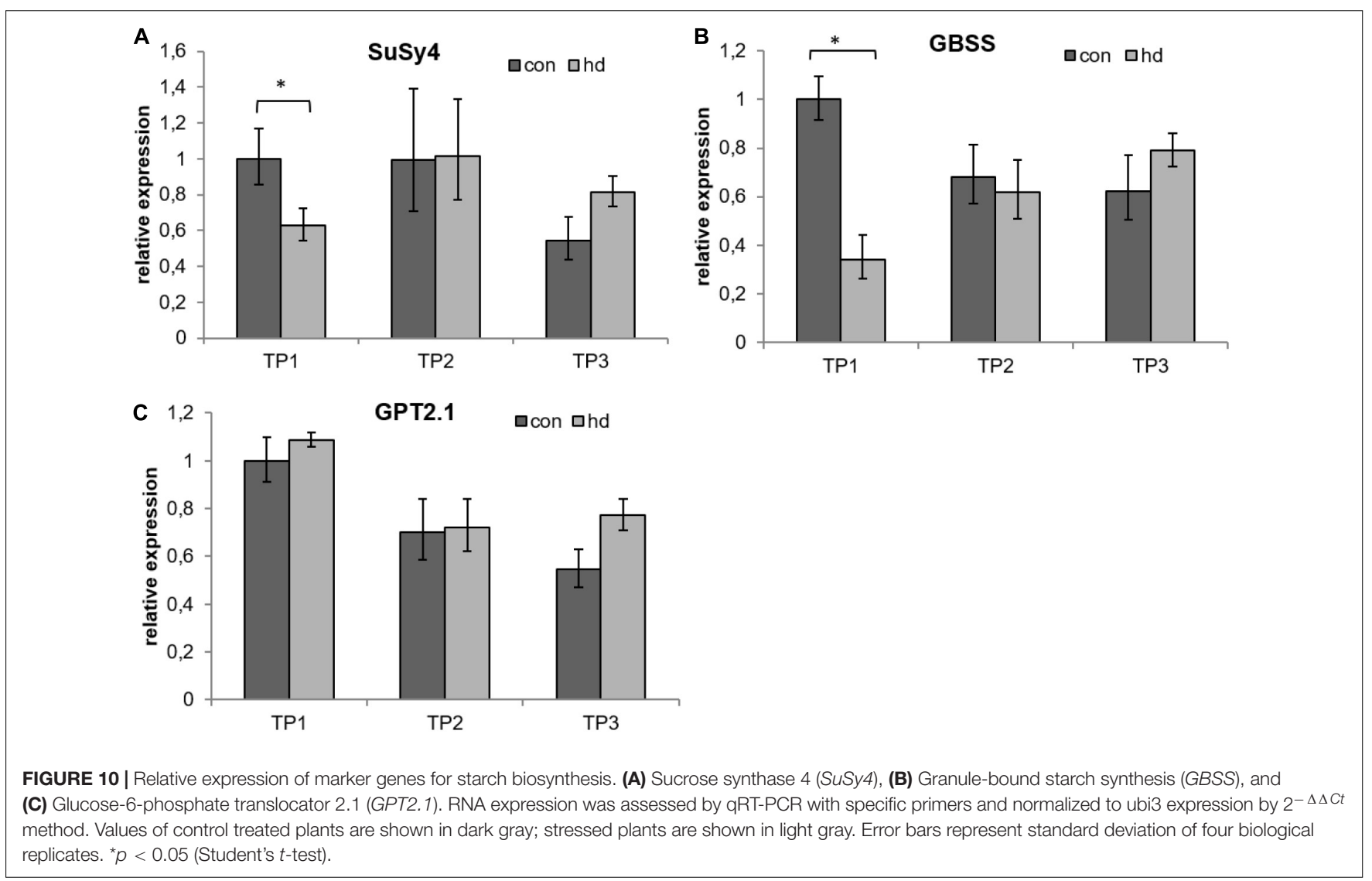

treatment (TP1) a marked decrease in SuSy4 expression in comparison to the control group was detected (Figure 10A). After the stress treatment (TP2) SuSy4 expression recovered to control level. At the end of the experimental period (TP3) SuSy4 expression in stress treated tubers exceeded the expression in control tubers Figure 10A). As a second starch metabolism marker, the expression of granule-bound starch synthase (GBSS) was analyzed. Similar to SuSy4, GBSS expression was found to be significantly down-regulated in tubers of the stressed group during the stress treatment (TP1) and to recover to control values after the stress (TP2 and 3, Figure 10B). Additionally, GPT2.1 expression was analyzed. During the stress treatment and 1 week after ending the treatment, no effect of the stress on GPT2.1 expression could be observed. At the end of the experimental period (TP3), GPT2.1 expression was slightly, but non-significantly higher in tubers grown under stress conditions than in tubers grown under control conditions (Figure 10C).

In summary, analysis of stress markers as well as markers for starch biosynthesis show that the biphasic growth curve 
is due to the combined drought and heat stress response which affects tuber biomass accumulation. Although starch content was not significantly affected by the stress treatment, biochemical and molecular biological parameters suggest an impact on tuber metabolism which is in line with the observation that tuber growth was inhibited by the stress treatment (Figure 7).

\section{DISCUSSION}

\section{Combined Heat and Drought Stress Affects Tuber Growth}

In this study, potato tuber development from initiation until harvest was monitored by CT analysis in stressed plants and plants grown under ambient conditions. We were able to establish an imaging pipeline to analyze the potato tuber delevopment in a high thoughput $(5 \mathrm{~min}$ per pot) and automated way (one set of parameter for the whole experiment). This enabled analyzing the stress dependend growth dynamic of individual tubers within one pot and to visualize even small variations in belowground biomass. The time dependance of this data set allowed the 4D analysis of growth processes affected by abiotic stresses. The imaging pipeline presented here can be scaled up to be used in highthroughput phenotyping systems. However, the combination with automated data processing is the key to generate objective data accelerating breeding efforts to improve abiotic stress tolerance.

We chose combined heat and drought stress since these abiotic stresses are likely to occur in parallel in the context of global climate change (Hijmans, 2003; Ahuja et al., 2010). We applied the stress treatment after tuber induction, when tubers were detectable by $\mathrm{CT}$, in order to avoid delaying or even completely inhibiting tuber formation. Such detrimental effects of heat and drought have been described previously (Jackson, 1999; Luitel et al., 2015; Dahal et al., 2019; Aliche et al., 2020). During combined stress application, CT analysis revealed that tuber growth is inhibited under combined elevated temperature and drought stress and most of the tubers can resume after the stress has been terminated. The growth arrest as calculated from the CT data led to significantly lower tuber biomass in stressed plants at the end of the stress treatment compared to control plants. After cessation of the stress, tubers started growing again and were only slightly smaller than control tubers at the end of the experimental period.

Due to the early timing of the stress treatment directly after tuber induction, it seems that most tubers were able to recover from the implications of the stress treatment on biomass accumulation. This was also seen in an early study on the effects of individual heat and drought stress on tuber development (Levy, 1985) where early stress, imposed when tubers were small, reduced tuber yield and dry matter accumulation only slightly. Heat or drought stress applied during the tuber bulking stage had a more deleterious effect on tuber yield (Levy, 1986, 1985). Moreover, in our experimental setup plants were still immature at the end of the experimental period, exhibiting only small tubers and low overall tuber biomass. How our findings translate to potato plants grown to maturity requires further trials.

\section{Stress Markers Respond to the Treatment}

Genes which have previously been shown to respond with differential expression during abiotic stress were selected from the literature (Rizhsky et al., 2002; Gong et al., 2015) in order to confirm that the stress led to a response in the potato tubers. Gong et al. (2015) analyzed gene transcription in stolon tips of potato plants grown under control conditions, drought stress and after re-watering. They found that TAS14 was 4.7-fold up-regulated after 3 days of drought treatment and 8.2-fold down-regulated after re-watering when compared to stolons from plants grown under control conditions. In our study, TAS14 expression in tubers was almost 50-fold upregulated after 8 days of combined drought and heat stress but had returned to values similar to control 3 days after stress release. This indicated that TAS14 might be suitable as a marker for stress in potato tubers. However, further characterization of its expression profile in different plant organs and under differing conditions is needed to confirm its suitability as a stress marker. Support for the role of TAS14 during abiotic stress comes from experiments in tomato, where stable overexpression of TAS14 led to improved long-term drought tolerance (Muñoz-Mayor et al., 2012).

Rizhsky et al. (2002) examined gene expression patterns under different stress conditions as well as their combinations in tobacco plants. A combination of drought and heat stress led to significant increases in gene expression of DI19 and Lox1, by 34- and 6.7-fold, respectively. DI19 has also been described in rice as a key regulator during drought stress and drought tolerance (Wang et al., 2014). In the present study, DI19 and Lox1 were induced significantly, but to a far lesser extent than in those previous studies, in tubers during combined stress treatment compared to tubers grown under control conditions. It appears that these two transcripts are not suitable as markers for combined heat and drought stress in potato tubers.

Heat-shock protein (DMT400032851) which was strongly elevated in potato tubers during combined heat and drought stress compared to control, has previously been found in a microarray analysis among 2,886 differentially expressed genes in potato tubers of the cultivar Desirée during mild heat (Hancock et al., 2014). In the experiment by Hancock et al. (2014), potato plants were subjected to elevated temperature $\left(30^{\circ} \mathrm{C}\right.$ during the day $/ 20^{\circ} \mathrm{C}$ during the night) for 1 week and expression patterns over a time course of $20 \mathrm{~h}$ were compared to tubers grown under ambient conditions $\left(22^{\circ} \mathrm{C}\right.$ / $16^{\circ} \mathrm{C}$ ). HSP was found to be upregulated approximately 12 -fold on average over time (range 0.8-30.8-fold) during elevated temperature. The strong induction which we have determined for HSP could be a result of the additional drought treatment and the different methodology (qRT-PCR vs. 
microarray analysis). Thus, HSP might be an appropriate marker for combined heat and drought stress in potato tubers but further validation is recommended.

\section{Combined Heat and Drought Stress Has a Negative Influence on Expression of Genes Encoding Enzymes Involved in Starch Biosynthesis}

Heat and drought are abiotic stress factors influencing many developmental and physiological processes. In potato plants, both factors, alone or in combination, affect tuberization and starch accumulation associated therewith (Bodlaender, 1963; Wolf et al., 1990; Gawronska et al., 1992). Depending on the timing of the occurrence of these disruptive environmental conditions, tuberization can be inhibited completely or tuber bulking can be disturbed (Tang et al., 2018). Furthermore, carbon partitioning can be altered by transient exposure of potato plants to heat stress leading to reduced starch and increased reducing sugar contents of tubers (Busse et al., 2019). We have seen a disturbance of tuber bulking which was confirmed by analysis of mRNA expression of SuSy4 as well as specific activity of SuSy, a marker for starch biosynthesis, in tuber samples. Increased SuSy expression and activity has been associated with increased starch and total yield (BarojaFernández et al., 2009). Under adverse conditions like heat, SuSy4 expression and SuSy activity have been shown decrease (Hastilestari et al., 2018).

GPT2.1 has been identified as the tuber-specific GPT2 isoform (Van Harsselaar et al., 2017), whose expression is strongly associated to processes linked to starch biosynthesis and correlates to SuSy4 expression (Ferreira et al., 2010). Therefore, we hypothesized that GPT2.1 expression would decrease during stress treatment. However, gene expression analysis of GPT2.1 revealed no significant differences between stressed tuber samples and tubers grown under control conditions. This is consistent with the gene expression data from tuber samples under elevated temperatures published by Hancock et al. (2014) and Hastilestari et al. (2018) where GPT2.1 was not among the differentially regulated genes.

Granule-bound starch synthase is the starch synthase isoform responsible for amylose-synthesis (Visser et al., 1989). Expression of GBSS was found to be significantly downregulated in potato tuber during combined heat and drought stress in our qRT-PCR analysis. Similarly, in the microarray experiment by Hancock et al. (2014), GBSS expression was downregulated significantly in the tuber samples from plants grown under elevated temperature. This seems consistent with an overall decrease of starch biosynthesis in potato tubers under heat and drought stress. In our experiment, SuSy4 and GBSS expression recovered to levels of tubers grown under control conditions after the stress conditions were released. Similar observations were reported by Chen et al. (2020) in potato leaves during re-watering after a dehydration period, where most genes which were differentially expressed during the dehydration period reversed their expression during re-watering.

\section{CT Analysis Pipeline Is a Phenotyping Tool for Stress Detection}

The presented imaging pipeline was able to generate stable results in growth analysis of potato tubers for five different genotypes. Using only one set of parameters it was possible to track individual tubers for different growth stages and a high variation in tuber number per plant. Thus, we demonstrated that this kind of CT analysis is a suitable tool to monitor morphological changes of otherwise inaccessible, underground tissues in planta and enables also methods like guided sampling to correlate in future morphological and physiological measurements. This is in accordance with for example Pfeifer et al. (2015) or Metzner et al. (2015). With the presented image pipeline for segmentation and feature calculation it is possible to track each individual potato tuber over time within the experiment. These time-resolved data were used for more detailed growth curve analysis like non-invasive biomass determination and the assessment of growth velocity. We could show that the observed biphasic growth pattern is directly connected with the heat and drought stress response in the tubers. This enabled us to use this CT based method together with the presented image pipeline to be a non-invasive tool for prediction of stress in potato tubers already in early growth stages. A major point was the presented combination of the individual $3 \mathrm{D}$ volume image analysis techniques. Doing so we could use only one set of input parameters for the extraction of the individual tubers for the whole experiment. Thus, the volume analysis toolchain was robust enough to handle the individual noise in the reconstructed volumes and the differences in moisture between well-watered and heat and drought stressed plants. For potato breeding purposes, this method could be used as a phenotyping platform for the development of stress resistant varieties. Additionally, the robust image pipeline and the relatively fast measurement times enables the observation of below ground tuber growth in high throughput. For future experiments it is possible to use pots up to a diameter of $20 \mathrm{~cm}$ and a volume of $4 \mathrm{~L}$ to analyze potato plants also in later growth stages. However, a deeper understanding of the processes and regulatory circuits elicited by drought, heat or both combined is required for potato in order to define parameters to distinguish stress tolerant and susceptible varieties. This is an important factor toward more resistant genotypes.

In general, the throughput of the system has to be evaluated in terms of cycle time in the measurement-including the measurement time and the time for sample exchange-and the time for data processing. The data processing time is directly connected to the computing power used for the analysis and with the data analysis pipeline presented a parallel computing can be realized. Thus, the processing time is not a bottleneck to further increase the overall throughput of the combined system. However, the current system was relying on a manual change of the individual plants. To further increase the cycling time of the system an integration in a conveyor system would be highly beneficial. Doing so, the time for sample exchange could be minimized. To decrease the measurement further, there are some more steps possible. 
The easiest one is to decrease the resolution and at the same time increase the smallest detectable tuber. This option is strongly connected with the breeding use case in mind. If this is not an option, using stronger X-ray sources or even pulsed sources is a way to decrease the scanning time. Finally, a vertical gantry system with pulsed $\mathrm{X}$-ray sources with rotating anodes would be a possibility for real high-throughput tuber analysis.

\section{DATA AVAILABILITY STATEMENT}

The raw data supporting the conclusions of this article will be made available by the authors, without undue reservation.

\section{AUTHOR CONTRIBUTIONS}

JC, SG, and JV performed the experiments and drafted the manuscript. JV did the molecular biological work. SG supervised and together with JC performed the CT

\section{REFERENCES}

Ahuja, I., De Vos, R. C. H., Bones, A. M., and Hall, R. D. (2010). Plant molecular stress responses face climate change. Trends Plant Sci. 15, 664-674. doi: 10.1016/ j.tplants.2010.08.002

Aksoy, E., Demİrel, U., Öztürk, Z. N., Çalişkan, S., Çalişkan, M. E., Demİrel, U., et al. (2015). Recent advances in potato genomics, transcriptomics, and transgenics under drought and heat stresses: a review. Turk. J. Bot. 39, 920-940. doi: 10.3906/bot-1506-25

Alexandratos, N., and Bruinsma, J. (2012). World agriculture towards 2015/2030: the 2012 revision. ESA Working Pap. 3:147. doi: 10.1016/S0264-8377(03) 00047-4

Aliche, E. B., Theeuwen, T. P. J. M., Oortwijn, M., Visser, R. G. F., and van der Linden, C. G. (2020). Carbon partitioning mechanisms in POTATO under drought stress. Plant Physiol. Biochem. 146, 211-219. doi: 10.1016/j.plaphy. 2019.11.019

ap Rees, T., Wright, B. W., and Fuller, W. A. (1977). Measurements of Starch breakdown as estimates of glycolysis during thermogenesis by the spadix of Arum maculatum L. Planta 134, 53-56. doi: 10.1007/BF003 90094

Appeldoorn, N. J. G., De Bruijn, S. M., Koot-Gronsveld, E. A. M., Visser, R. G. F., Vreugdenhil, D., and Van der Plas, L. H. W. (1997). Developmental changes of enzymes involved in conversion of sucrose to hexose-phosphate during early tuberisation of potato. Planta 202, 220-226. doi: 10.1007/s004250 050122

Baroja-Fernández, E., Muñoz, F. J., Montero, M., Etxeberria, E., Sesma, M. T., Ovecka, M., et al. (2009). Enhancing sucrose synthase activity in transgenic potato (Solanum tuberosum L.) Tubers results in increased levels of starch, ADPglucose and UDPglucose and total yield. Plant Cell Physiol. 50, 1651-1662. doi: $10.1093 / \mathrm{pcp} / \mathrm{pcp} 108$

Bodlaender, K. B. A. (1963). Influence of temperature, radiation and photoperiod on development and yield. Growth Potato 3, 199-210.

Bradford, M. M. (1976). A rapid and sensitive method for the quantitation of microgram quantities of protein utilizing the principle of proteindye binding. Anal. Biochem. 72, 248-254. doi: 10.1016/0003-2697(76) 90527-3

Busse, J. S., Wiberley-Bradford, A. E., and Bethke, P. C. (2019). Transient heat stress during tuber development alters post-harvest carbohydrate composition and decreases processing quality of chipping potatoes. J. Sci. Food Agricult. 99, 2579-2588. doi: 10.1002/jsfa. 9473 work. NW and JC performed the image and data analysis. US and NU provided the project funding, conceived and led the study, and contributed to writing the manuscript. US, SG, and JL discussed the work and the biphasic growth pattern. All authors read and approved the final manuscript.

\section{FUNDING}

The work was supported by Fachagentur Nachwachsende Rohstoffe (22010712, 22010812, and 22032711).

\section{ACKNOWLEDGMENTS}

We would like to thank Kim Schwanhäußer for helping with potato harvest and Christine Hösl for transfer of plantlets. We would also like to thank Anna-Maria Bachmann for support with plant care.

Buzug, T. (2008). Computed Tomography. Computed Tomography: From Photon Statistics to Modern Cone-Beam CT. Berlin: Springer. doi: 10.1007/978-3-54039408-2

Chen, Y., Li, C., Yi, J., Yang, Y., Lei, C., and Gong, M. (2020). Transcriptome response to drought, rehydration and re-dehydration in potato. Int. J. Mol. Sci. 21:159. doi: 10.3390/ijms21010159

Ciais, P., Reichstein, M., Viovy, N., Granier, A., Ogée, J., Allard, V., et al. (2005). Europe-wide reduction in primary productivity caused by the heat and drought in 2003. Nature 437, 529-533. doi: 10.1038/nature 03972

Cook, E. R., Seager, R., Cane, M. A., and Stahle, D. W. (2007). North American drought: reconstructions, causes, and consequences. Earth Sci. Rev. 81, 93-134. doi: 10.1016/j.earscirev.2006.12.002

Dahal, K., Li, X. Q., Tai, H., Creelman, A., and Bizimungu, B. (2019). Improving potato stress tolerance and tuber yield under a climate change scenario - a current overview. Front. Plant Sci. 10:563. doi: 10.3389/fpls.2019. 00563

Deblonde, P. M. K., and Ledent, J. F. (2001). Effects of moderate drought conditions on green leaf number, stem height, leaf length and tuber yield of potato cultivars. Eur. J. Agron. 14, 31-41. doi: 10.1016/S1161-0301(00) 00081-2

Delgado, A., Hays, D. B., Bruton, R. K., Ceballos, H., Novo, A., Boi, E., et al. (2017). Ground penetrating radar: a case study for estimating root bulking rate in cassava (Manihot Esculenta Crantz). Plant Methods 13, 1-11. doi: 10.1186/ s13007-017-0216-0

Duong Quoc Le, T., Alvarado, C., Girousse, C., Legland, D., and Chateigner-Boutin, A.-L. (2019). Use of X-ray micro computed tomography imaging to analyze the morphology of wheat grain through its development. Plant Methods 15:84. doi: 10.1186/s13007-0190468-y

Ferreira, S. J., Senning, M., Sonnewald, S., Kessling, P.-M., Goldstein, R., and Sonnewald, U. (2010). Comparative transcriptome analysis coupled to X-ray CT reveals sucrose supply and growth velocity as major determinants of potato tuber starch biosynthesis. BMC Genom. 11:93. doi: 10.1186/1471-21 64-11-93

Fu, H., and Park, W. D. (1995). Sink- and vascular-associated sucrose synthase functions are encoded by different gene classes in potato. Plant Cell 7, 13691385. doi: 10.1105/tpc.7.9.1369

Gao, W., Schlüter, S., Blaser, S. R. G. A., Shen, J., and Vetterlein, D. (2019). A Shape-based method for automatic and rapid segmentation of roots in soil from X-ray computed tomography images: rootine. Plant Soil 441, 643-655. doi: 10.1007/s11104-019-04053-6 
Gawronska, H., Thornton, M. K., and Dwelle, R. B. (1992). Influence of heat stress on dry matter production and photoassimilate partitioning by four potato clones. Am. Potato J. 69, 653-665. doi: 10.1007/bf028 52678

Gong, L., Zhang, H., Gan, X., Zhang, L., Chen, Y., Nie, F., et al. (2015). Transcriptome profiling of the potato (Solanum tuberosum L.) plant under drought stress and water-stimulus conditions. PLoS One 10:e0128041. doi: 10. 1371/journal.pone.0128041

Hancock, R. D., Morris, W. L., Ducreux, L. J. M., Morris, J. A., Usman, M., Verrall, S. R., et al. (2014). Physiological, biochemical and molecular responses of the potato (Solanum tuberosum L.) plant to moderately elevated temperature. Plant Cell Environ. 37, 439-450. doi: 10.1111/pce. 12168

Hastilestari, B. R., Lorenz, J., Reid, S., Hofmann, J., Pscheidt, D., Sonnewald, U., et al. (2018). Deciphering source and sink responses of potato plants (Solanum tuberosum L.) to elevated temperatures. Plant Cell Environ. 41, 2600-2616. doi: $10.1111 /$ pce. 13366

Hijmans, R. J. (2003). The effect of climate change on global potato production. Am. J. Potato Res. 80, 271-279. doi: 10.1007/BF02855363

Hughes, N., Askew, K., Scotson, C. P., Williams, K., Sauze, C., Corke, F., et al. (2017). Non-destructive, high-content analysis of wheat grain traits using X-ray micro computed tomography. Plant Methods 13:76. doi: 10.1186/s13007-0170229-8

Jackson, S. D. (1999). Multiple Signaling Pathways Control Tuber Induction in Potato. Plant Physiology 119, 1-8. doi: 10.1104/pp.119.1.1

Kloosterman, B., Vorst, O., Hall, R. D., Visser, R. G. F., and Bachem, C. W. (2005). Tuber on a chip: differential gene expression during potato tuber development. Plant Biotechnol. J. 3, 505-519. doi: 10.1111/j.1467-7652.2005. 00141.x

Krauss, A., and Marschner, H. (1984). Growth rate and carbohydrate metabolism of potato tubers exposed to high temperatures. Potato Res. 27, 297-303. doi: $10.1007 / \mathrm{bf} 02357638$

Levy, D. (1985). The response of potatoes to a single transient heat or drought stress imposed at different stages of tuber growth. Potato Res. 28, 415-424. doi: $10.1007 / \mathrm{BF} 02357516$

Levy, D. (1986). Genotypic variation in the response of potatoes (Solanum tuberosum 1.) to high ambient temperatures and water deficit. Field Crops Res. 15, 85-96. doi: 10.1016/0378-4290(86)90103-6

Li, L., Paulo, M.-J., Strahwald, J., Lübeck, J., Hofferbert, H.-R., Tacke, E., et al. (2008). Natural DNA variation at candidate loci is associated with potato chip color, tuber starch content, yield and starch yield. Theoret. Angew. Genet. 116, 1167-1181. doi: 10.1007/s00122-0080746-y

Logemann, J., Schell, J., and Willmitzer, L. (1987). Improved method for the isolation of RNA from plant tissues. Anal. Biochem. 163, 16-20. doi: 10.1016/ 0003-2697(87)90086-8

Luitel, B. P., Khatri, B. B., Choudhary, D., Paudel, B. P., Jung-Sook, S., Hur, O. S., et al. (2015). Growth and yield characters of potato genotypes grown in drought and irrigated conditions of nepal. Int. J. Appl. Sci. Biotechnol. 3, 513-519. doi: 10.3126/ijasbt.v3i3.13347

Metzner, R., Eggert, A., van Dusschoten, D., Pflugfelder, D., Gerth, S., Schurr, U., et al. (2015). Direct comparison of MRI and X-Ray CT technologies for 3D Imaging of root systems in soil: potential and challenges for root trait quantification. Plant Methods 11:17. doi: 10.1186/s13007-0150060-z

Mooney, S. J., Pridmore, T. P., Helliwell, J., and Bennett, M. J. (2012). Developing X-Ray computed tomography to non-invasively image 3-D root systems architecture in soil. Plant Soil 352, 1-22. doi: 10.1007/s11104-0111039-9

Muñoz-Mayor, A., Pineda, B., Garcia-Abellán, J. O., Antón, T., GarciaSogo, B., Sanchez-Bel, P., et al. (2012). Overexpression of dehydrin tas14 gene improves the osmotic stress imposed by drought and salinity in tomato. J. Plant Physiol. 169, 459-468. doi: 10.1016/j.jplph.2011. 11.018

Murashige, T., and Skoog, F. (1962). A revised medium for rapid growth and bio assays with tobacco tissue cultures. Physiol. Plant. 15, 473-497. doi: 10.1111/j. 1399-3054.1962.tb08052.x
Navarro, C., Abelenda, J. A., Cruz-Oró, E., Cuéllar, C. A., Tamaki, S., Silva, J., et al. (2011). Control of flowering and storage organ formation in potato by Flowering locus T. Nature 478, 119-122. doi: 10.1038/nature 10431

Pérez-Torres, E., Kirchgessner, N., Pfeifer, J., and Walter, A. (2015). Assessing potato tuber diel growth by means of X-Ray computed tomography. Plant Cell Environ. 38, 2318-2326. doi: 10.1111/pce.12548

Pfeifer, J., Kirchgessner, N., Colombi, T., and Walter, A. (2015). Rapid Phenotyping of crop root systems in undisturbed field soils using X-Ray computed tomography. Plant Methods 11:41. doi: 10.1186/s13007-0150084-4

Rizhsky, L., Liang, H., and Mittler, R. (2002). The combined effect of drought stress and heat shock on gene expression in tobacco. Plant Phisiol. 130, 1143-1151. doi: $10.1104 /$ pp.006858.then

Rogers, E. D., Monaenkova, D., Mijar, M., Nori, A., Goldman, D. I., and Benfey, P. N. (2016). X-Ray computed tomography reveals the response of root system architecture to soil texture. Plant Physiol. 171, 2028-2040. doi: 10.1104/pp.16. 00397

Schmidt, J., Claussen, J., Wörlein, N., Eggert, A., Fleury, D., Garnett, T., et al. (2020). Drought and heat stress tolerance screening in wheat using computed tomography. Plant Methods 16, 1-12. doi: 10.1186/s13007-020-0 0565-w

Soille, P. (1998). Erosion Und Dilatation: Morphologische Bildverarbeitung. Berlin: Springer, 51-93. doi: 10.1007/978-3-642-72190-8_3

Tang, R., Niu, S., Zhang, G., Chen, G., Haroon, M., Yang, Q., et al. (2018). Physiological and growth responses of potato cultivars to heat stress. Botany 96, 897-912. doi: 10.1139/cjb-2018-0125

Teramoto, S., Takayasu, S., Kitomi, Y., Arai-Sanoh, Y., Tanabata, T., and Uga, Y. (2020). High-throughput three-dimensional visualization of root system architecture of rice using X-ray computed tomography. Plant Methods 16:66. doi: 10.1186/s13007-020-00612-6

Thiele, G., Theisen, K., Bonierbale, M., and Walker, T. (2010). Targeting the poor and hungry with potato science. Potato J. 37, 75-86.

Tracy, S. R., Roberts, J. A., Black, C. R., McNeill, A., Davidson, R., and Mooney, S. J. (2010). The X-factor: visualizing undisturbed root architecture in soils using X-Ray computed tomography. J. Exp. Bot. 61, 311-313. doi: 10.1093/jxb/ erp386

Van Dam, J., Kooman, P. L., and Struik, P. C. (1996). Effects of Temperature and photoperiod on early growth and final number of tubers in potato (Solanum tuberosum L.). Potato Res. 39, 51-62. doi: 10.1007/bf02 358206

van Dusschoten, D., Metzner, R., Kochs, J., Postma, J. A., Pflugfelder, D., and Bühler, J. (2016). Quantitative 3D analysis of plant roots growing in soil using magnetic resonance imaging. Plant Physiol. 170, 1176-1188. doi: 10.1104/pp.15. 01388

Van Harsselaar, J. K., Lorenz, J., Senning, M., Sonnewald, U., and Sonnewald, S. (2017). Genome-wide analysis of starch metabolism genes in potato (Solanum tuberosum L.). BMC Genom. 18:3381. doi: 10.1186/s12864-0163381-Z

Viola, R., Roberts, A. G., Haupt, S., Gazzani, S., Hancock, R. D., Marmiroli, N., et al. (2001). Tuberization in potato involves a switch from apoplastic to symplastic phloem unloading. Plant Cell 13, 385-398. doi: 10.2307/38 71283

Visser, R. G. F., Hergersberg, M., Van Der Leij, F. R. R., Jacobsen, E., Witholt, B., and Feenstra, W. J. J. (1989). Molecular cloning and partial characterization of the gene for granule-bound starch synthase from a wildtype and an amylosefree potato (Solanum tuberosum L.). Plant Sci. 64, 185-192. doi: 10.1016/01689452(89)90023-X

Wang, L., Yu, C., Chen, C., He, C., Zhu, Y., and Huang, W. (2014). Identification of rice Di19 family reveals OsDi19-4 involved in drought resistance. Plant Cell Rep. 33, 2047-2062. doi: 10.1007/s00299-014-1679-3

Wolf, S., Marani, A., and Rudich, J. (1990). Effect of temperature on carbohydrate metabolism in potato plants. J. Exp. Bot. 42, 619-625. doi: 10.1093/jxb/42.5.619

Yang, W., Xu, X., Duan, L., Luo, Q., Chen, S., Zeng, S., et al. (2011). Highthroughput measurement of rice tillers using a conveyor equipped with X-Ray computed tomography. Rev. Sci. Instrumen. 82:025102. doi: 10.1063/1.35 31980 
Ye, J., Coulouris, G., Zaretskaya, I., Cutcutache, I., Rozen, S., and Madden, T. L. (2012). Primer-BLAST: a tool to design target-specific primers for polymerase chain reaction. BMC Bioinform. 13:134. doi: 10.1186/1471-2105-13-134

Zappala, S., Mairhofer, S., Tracy, S., Sturrock, C. J., Bennett, M., Pridmore, T., et al. (2013). Quantifying the effect of soil moisture content on segmenting root system architecture in X-Ray computed tomography images. Plant Soil 370, 35-45. doi: 10.1007/s11104-013-1596-1

Zrenner, R., Salanoubat, M., Willmitzer, L., and Sonnewald, U. (1995). Evidence of the crucial role of sucrose synthase for sink strength using transgenic potato plants (Solanum tuberosum L.). Plant J. 7, 97-107. doi: 10.1046/j.1365-313x. 1995.07010097.x
Conflict of Interest: The authors declare that the research was conducted in the absence of any commercial or financial relationships that could be construed as a potential conflict of interest.

Copyright $\odot 2021$ Van Harsselaar, Claußen, Lübeck, Wörlein, Uhlmann, Sonnewald and Gerth. This is an open-access article distributed under the terms of the Creative Commons Attribution License (CC BY). The use, distribution or reproduction in other forums is permitted, provided the original author(s) and the copyright owner(s) are credited and that the original publication in this journal is cited, in accordance with accepted academic practice. No use, distribution or reproduction is permitted which does not comply with these terms. 